\title{
PENGARUH PENAMBAHAN UNSUR NIKEL/ KARBON PADA DEPOSIT LAS ELEKTRODA E6013 TERHADAP SIFAT MEKANIK
}

\author{
${ }^{1)}$ Syaripuddin, 1)Khotijah Rohma \& ${ }^{2)}$ Ferry Budhi Susetyo \\ 1)Program Studi Pendidikan Teknik Mesin, Fakultas Teknik, Universitas Negeri Jakarta \\ 2)Program Studi Teknik Mesin, Fakultas Teknik, Universitas Negeri Jakarta \\ E-mail: syaripuddin_andre@yahoo.com
}

\begin{abstract}
ABSTRAK
Penelitian ini bertujuan untuk mengetahui adakah pengaruh pelapisan nikel dan penambahan unsur karbon pada elektroda E6013 terhadap sifat mekanik hasil pengelasan baja karbon rendah yang menyangkut nilai kekerasan. Metode dalam penelitian ini adalah metode eksperimen. Penelitian ini menggunakan jenis baja berkarbon rendah yang mengandung unsur kimia 0,158\% C, 0,013\% Si, 0,86\% Mg, 0,015\% Fosfor, 0,016 \% S dan 98,9\% Fe. Lalu menggunakan elektroda E6013 di elektroplating Nikel dan adanya penambahan unsur Karbon.. Pengelasan menggunakan jenis las SMAW. Hasil penelitian menunjukkan bahwa nilai kekerasan paling tinggi terdapat pada sambungan SMAW pelat baja yang di las menggunakan elektroda yang telah dilapisi Nikel dan ditambahkan Karbon. Dengan menambahkan Nikel kekerasan pada permukaan baja yang di las lebih meningkat dari 144.8 VHN menjadi 278.86 VHN. Dengan menambahkan Karbon kekerasan pada permukaan baja lebih meningkat dari 144.8 VHN menjadi 247.9 VHN. Dengan menambahkan Nikel dan Karbon kekerasan pada permukaan baja lebih meningkat dari 132.28 VHN menjadi 445.88 VHN.
\end{abstract}

Kata kunci: SMAW, Elektroplating, Nikel, Karbon, Struktur Mikro, dan Kekerasan, E6013

\section{Pendahuluan}

Penggunaan aplikasi las bukan hanya untuk teknik penyambungan dua material logam, tetapi juga dapat digunakan untuk menambah ketebalan dari komponen mesin yang mengalami keausan atau pada komponen yang akan mengalami gesekan. Teknik teknik las penebalan ini banyak digunakan untuk komponen komponen yang mudah aus seperti pada alat berat, misalnya scoops lift bucket dan Ripper Teeth pada excavator. Dalam dunia alat-alat berat pasti ada bagian yang rusak dan aus, dikarenakan pada saat penggalian tanah, pengumpulan tanah, pengangkutan tanah pada saat alat berat sedang bekerja.(Iskandar, 2013)

Teknik mengelas untuk penebalan pada suatu material untuk meningkatkan kekerasaan pada permukaan melalui metode pengelasan disebut hardfacing. Beberapa keuntungan yang bisa diperoleh dari metode pengelasan hardfacing, adalah hasil lasnya memiliki tingkat kekerasan yang tinggi, ketahanan aus yang tinggi, menghemat pemakaian baja paduan yang mahal, menurunkan cost, serta tersedianya berbagai macam material yang siap digunakan dengan metode ini. (Prayitno Dkk, 2013)

Teknik hardfacing sendiri menggunakaan elektroda yang sudah tersedia di pasaran. Dapat menggunakan HV 350, 450, 600, 800 atau masih banyak jenis yang lain. Dalam elektroda tersebut komposisi unsur yang menyebabkan peningkatan sifat kekerasan adalah nikel, karbon dan krom. Penambahan unsur nikel dapat dilakukan dengan proses elektroplating. Proses elekroplating merupakan suatu proses yang mudah jika dibandingkan dengan proses peleburan (melting). (Sugiyarta Dkk, 2012)

Pada proses tersebut unsur nikel pada elektroda E 6013 yang mempunyai komposisi $(\mathrm{C}=0.20)(\mathrm{Mn}=$ 1.20) $(\mathrm{Si}=1.0)(\mathrm{P}=0.04)(\mathrm{S}=0.035)$ akan bertambah. Kemudian ditambahkan juga unsur karbon pada saat pengelasan, sehingga diharapkan akan meningkatkan nilai kekerasan dari lapisan yang terbentuk.

\section{Metodologi}

Prosedur penelitian ini mengikuti tahapan yang harus dilalui mulai dari pelapisan elektroda sampai dengan tahap pengujian.

a. Proses Pelapisan

1. Elektroda dibersihkan dengan palu untuk menghilangkan Fluks.

2. Elektroda diamplas untuk menghilangkan Fluks.

3. Melakukan penimbangan berat elektroda menggunakan timbangan digital guna mengetahui hasil yang didapat setelah proses pelapisan.

4. Menyiapkan larutan yang akan digunakan untuk electroplating. Komposisi Larutan Elektrolit Nikel yang berisi $\mathrm{NiSO}_{4}$ (Nikel Sulfat) sebesar $250 \mathrm{gr} / \mathrm{lt}, \mathrm{NiCl}$ (Nikel Chlorid) sebesar $40 \mathrm{gr} / \mathrm{lt}$ dan $\mathrm{H}_{3} \mathrm{BO}_{3}$ (Asam Borat ) sebesar $30 \mathrm{gr} / \mathrm{lt}$.

5. Melakukan pelapisan Nikel untuk elektroda E6013 dilakukan pada tegangan 5 volt dan arus 1 Ampere selama 15 menit. 
6. Dibersihkan dengan aquades, kemudian dikeringkan.

7. Melakukan perhitungan hasil lapisan pada Elektroda dengan menggunakan timbangan digital.

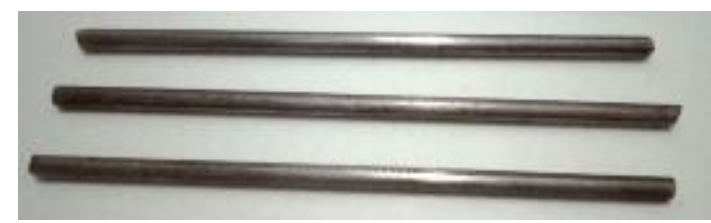

Gambar 1. Elektroda yang sudah di bersihkan

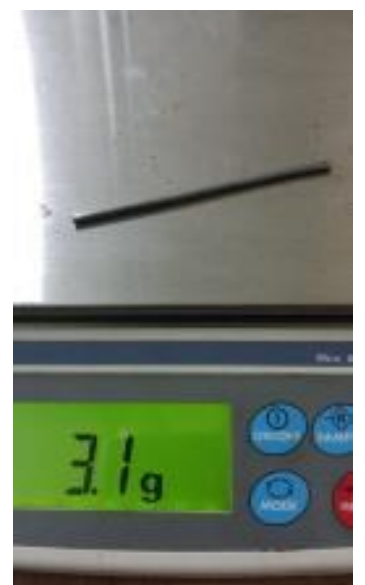

Gambar 2. Pengukuran Berat Elektroda sebelum pelapisan

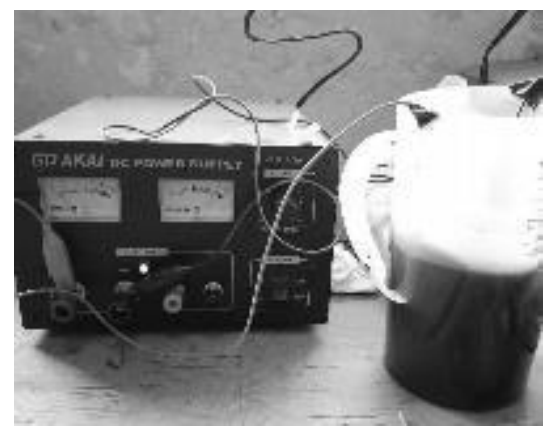

Gambar 3. Proses pelapisan elektroda dengan Nikel

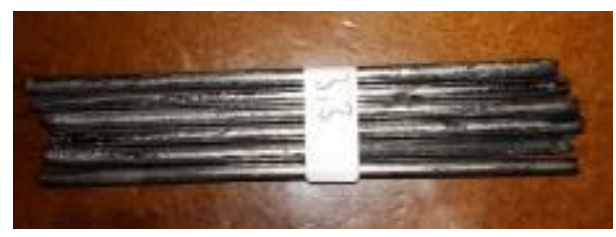

Gambar 4. Hasil pelapisan Elektroda dengan Nikel

b. Proses Pengelasan

Membuat Spesimen berjumlah 4 spesimen dengan polaritas DC+ dan Arus 95A dengan diameter elektroda 2.6 yang terdiri 4 spesimen yaitu Elektroda E6013, Elektroda E6013 yang dilapisi Nikel, Elektroda E6013 yang ditambah Karbon sebesar 0.6 g dan Elektroda E6013 yang telah dilapisi Nikel dan ditambah Karbon. Dengan ukuran 100 x 25 mm untuk setiap spesimennya.

Tabel 1. Diagram Diameter dan Arus Elektroda

\begin{tabular}{|c|c|c|c|c|c|c|c|}
\hline \multirow{2}{*}{$\begin{array}{c}\text { WELDING } \\
\text { AMPERAGE }\end{array}$} & $\begin{array}{c}\varnothing \\
(\mathrm{mm})\end{array}$ & 1.6 & 2.0 & 2.6 & 3.2 & 4.0 & 5.0 \\
\cline { 2 - 9 } & MIN & 20 & 30 & 60 & 80 & 120 & 160 \\
AC or DC & MAX & 40 & 80 & 110 & 140 & 190 & 230 \\
\hline
\end{tabular}

Menyiapkan elektroda yang dilapisi nikel diatas baja karbon rendah, lalu memberi titik lasan diujung kiri dan kanan elektroda. 


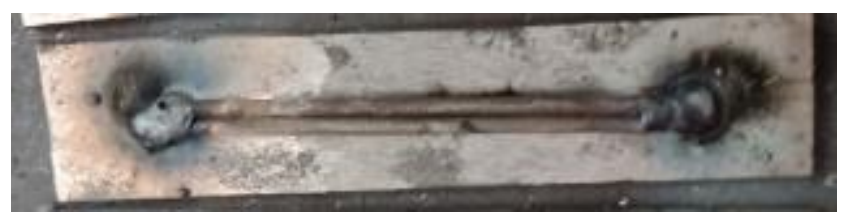

Gambar 5. Persiapan elektroda terlapis Nikel yang akan dilas

Menyiapkan elektroda E6013 diatas baja karbon rendah, kemudian di beri titik di ujung kanan dan kiri elektroda, lalu menambahkan unsur Karbon diatasnya.

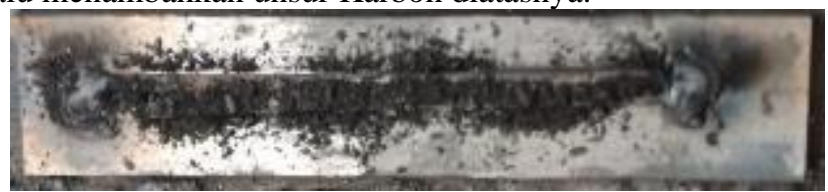

Gambar 6. Persiapan pengelasan dengan penambahan Karbon

Menyiapkan elektroda E6013 yang telah dilapisi nikel diatas baja karbon rendah, kemudian di beri titik di ujung kanan dan kiri elektroda, lalu menambahkan unsur Karbon diatasnya.

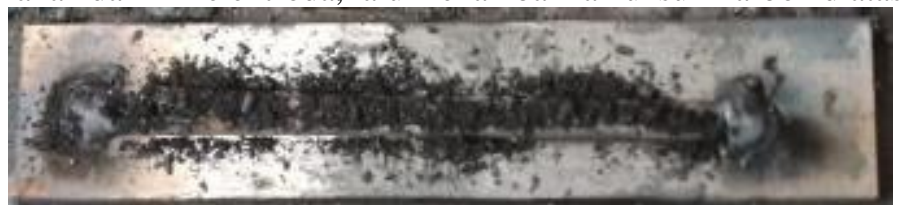

Gambar 7. Persiapan pengelasan dengan penambahan Karbon pada elektroda yang telah dilapisi Nikel

Setelah menyiapkan alat dan bahan pengelasan, lalu dilakukan proses pengelasan dengan hasil seperti gambar 8 .

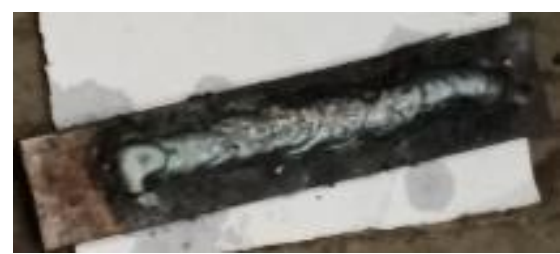

Gambar 8. Hasil pengelasan

Setelah selesai di las kemudian spesimen tersebut didinginkan dengan air. Spesimen tersebut terdiri dari yaitu terdiri dari plat hasil las dengan elektroda E6013, plat hasil las dengan elektroda E6013 yang sudah dilapisi Nikel, plat hasil las elektroda E6013 yang ditambahkan karbon dan plat hasil las dengan elektroda E6013 yang dilapisi Nikel dan ditambahkan karbon. Setelah masing - masing spesimen dipotong dengan gergaji, dengan hasil seperti gambar 9.

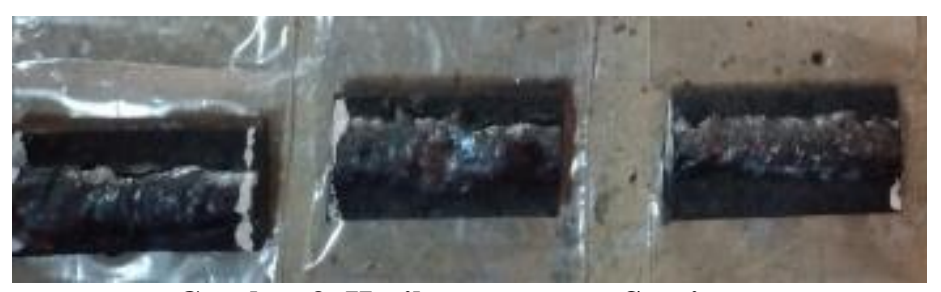

Gambar 9. Hasil pemotongan Spesimen

c. Proses Grinding

Plat hasil pengelasan dengan ukuran $100 \times 25 \mathrm{~mm}$ lalu bagian-bagian dipotong menjadi $50 \times 25 \mathrm{~mm}$, kemudian akan digerinda untuk mendapatkan permukaan yang rata. Proses grinding akan dilakukan menggunakan surface grinding machine. Setelah spesimen melalui proses grinding, maka langkah selanjutnya adalah akan dilakukan uji kekerasan dengan menggunakan metode Vickers. 


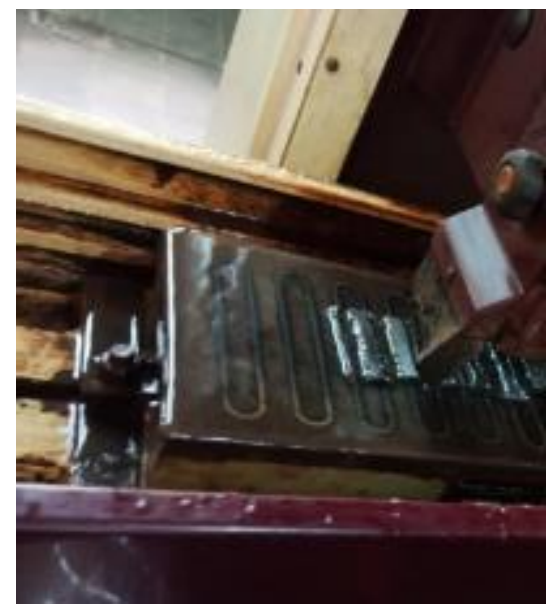

Gambar 10. Proses Meratakan Permukaan

d. Proses Uji Kekerasan

Langkah - Langkah yang dilakukan dalam proses uji kekerasan sebagai berikut:

1. Menyiapkan spesimen uji sebanyak 4 spesimen akan diuji.

2. Memastikan mesin uji kekerasan siap digunakan.

3. Kemudian ikuti penggunaan mesin uji kekerasan Vickers sesuai dengan SOP (Standar Operasional Prosedur) yang telah ada.

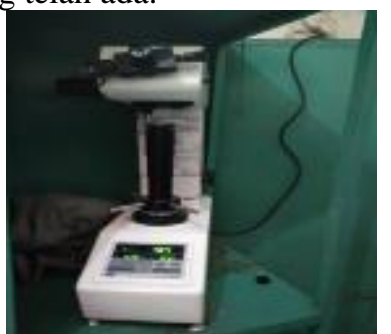

\section{Gambar 11. Proses Uji Kekerasan Vickers}

e. Pemolesan Spesimen untuk pengamatan struktur mikro

1. Siapkan amplas dan spesimen yang akan digunakan untuk proses pemolesan.

2. Kemudian spesimen diamplas menggunakan mesin poles, dimulai dengan amplas tingkat kekasaran 120, 200, 800, sampai kekasaran 1500

3. Setelah itu, poleslah spesimen ditambah dengan autosol diatas kain flanel agar mendapatkan hasil yang mengkilap seperti kaca.

4. Setelah spesimen sudah terlihat seperti kaca, langkah selanjutnya pengetsaan.

f. Pembuatan Spesimen untuk Uji Struktur Mikro

1. Membuat larutan alkohol $96 \%$ dicampur dengan asam $\mathrm{HNO}_{3} 4 \%$

2. Setelah larutan etsa jadi, selanjutnya adalah langkah untuk mencelupkan spesimen kedalam larutan etsa pada waktu yang berbeda untuk setiap spesimen.

3. Setelah dicelupkan dalam waktu tertentu, kemudian spesimen dikeringkan menggunakan hair dryer.

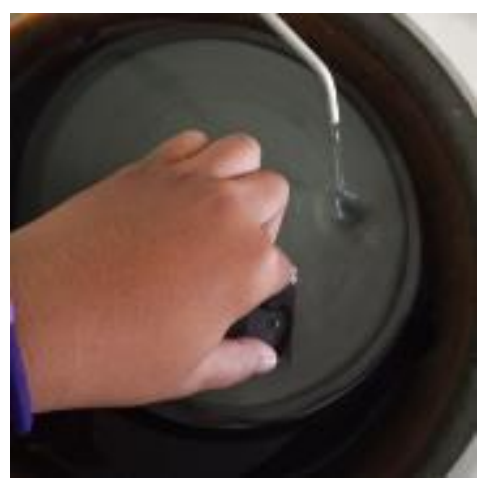




\section{Gambar 12. Proses Pemolesan dengan Mesin Poles}

g. Pengujian Komposisi

1. Menyiapkan bahan untuk uji komposisi yaitu elektroda karbon dan elektroda nikel.

2. Dilakukan pengujian Optical Emission Spectroscopy (OES) di Universitas Indonesia.

\section{Hasil dan Pembahasan}

\subsection{Hasil Uji OES}

- Hasil Uji komposisi Elektroda E6013 + Karbon

Setelah melakukan Uji Komposisi pada spesimen elektroda E6013 + Karbon diperoleh hasil kadar Karbon $(0.213 \%)$

Tabel 3. Hasil Uji komposisi Elektroda E6013 + Karbon

\begin{tabular}{|c|c|c|c|c|c|c|}
\hline $\begin{array}{c}\mathrm{C} \\
(\%)\end{array}$ & $\begin{array}{c}\mathrm{Si} \\
(\%)\end{array}$ & $\begin{array}{c}\mathrm{Mn} \\
(\%)\end{array}$ & $\begin{array}{c}\mathrm{P} \\
(\%)\end{array}$ & $\begin{array}{c}\mathrm{S} \\
(\%)\end{array}$ & $\begin{array}{c}\mathrm{Cr} \\
(\%)\end{array}$ & $\begin{array}{c}\mathrm{Mo} \\
(\%)\end{array}$ \\
\hline 0.213 & 0.122 & 0.216 & 0.018 & 0.016 & 0.076 & 0.008 \\
\hline $\begin{array}{c}\mathrm{Ni} \\
(\%)\end{array}$ & $\begin{array}{c}\mathrm{Al} \\
(\%)\end{array}$ & $\begin{array}{c}\mathrm{Cu} \\
(\%)\end{array}$ & $\begin{array}{c}\mathrm{Nb} \\
(\%)\end{array}$ & $\begin{array}{c}\mathrm{Ti} \\
(\%)\end{array}$ & $\begin{array}{c}\mathrm{V} \\
(\%)\end{array}$ & $\begin{array}{c}\mathrm{Fe} \\
(\%)\end{array}$ \\
\hline 0.029 & $<0.001^{* *}$ & 0.117 & 0.004 & 0.008 & 0.014 & bal. \\
\hline
\end{tabular}

- Hasil Uji komposisi Elektroda E6013 + Nikel

Setelah melakukan Uji Komposisi pada spesimen elektroda E6013 + Karbon diperoleh hasil kadar Nikel sebesar $0.409 \%$ dan Chrome sebesar $0.086 \%$. Dengan adanya penambahan kadar Nikel dan Chrome dapat diperoleh kesimpulan bahwa kekerasan bertambah berdasarkan peningkatan kadar unsur Nikel dan Chrome.

Tabel 4. Hasil Uji komposisi Elektroda E6013 + Nikel

\begin{tabular}{|c|c|c|c|c|c|c|}
\hline $\begin{array}{c}\mathrm{C} \\
(\%)\end{array}$ & $\begin{array}{c}\mathrm{Si} \\
(\%)\end{array}$ & $\begin{array}{c}\mathrm{Mr} \\
(\%)\end{array}$ & $\begin{array}{c}\mathrm{P} \\
(\%)\end{array}$ & $\begin{array}{c}\mathrm{S} \\
(\%)\end{array}$ & $\begin{array}{c}\mathrm{Cr} \\
(\%)\end{array}$ & $\begin{array}{c}\mathrm{Mio} \\
(\%)\end{array}$ \\
\hline 0.115 & 0.124 & 0.224 & 0.018 & 0.018 & 0.086 & 0.009 \\
\hline $\begin{array}{c}\mathrm{Ni} \\
(\%)\end{array}$ & $\begin{array}{c}\Delta l \\
(\%)\end{array}$ & $\begin{array}{c}\mathrm{Cu} \\
(\%)\end{array}$ & $\begin{array}{c}\mathrm{Nb} \\
(\%)\end{array}$ & $\begin{array}{c}\mathrm{Ti} \\
(\%)\end{array}$ & $\begin{array}{c}\mathrm{V} \\
(\%)\end{array}$ & $\begin{array}{c}\mathrm{Pe} \\
(\%)\end{array}$ \\
\hline 0.409 & $<0.001 * *$ & 0.109 & $<0.002 *$ & 0.005 & 0.008 & bal. \\
\hline
\end{tabular}

- Hasil Uji komposisi Elektroda E6013 + Nikel + Karbon

Setelah melakukan Uji Komposisi pada spesimen elektroda E6013 + Karbon diperoleh hasil kadar Nikel sebesar $0.095 \%$ dan kadar karbon sebesar $0.163 \%$. Dengan adanya penambahan kadar Nikel dan Karbon dapat diperoleh kesimpulan bahwa kekerasan bertambah berdasarkan peningkatan kadar unsur Nikel dan Karbon.

Tabel 5. Hasil Uji komposisi Elektroda E6013 + Nikel + Karbon

\begin{tabular}{|c|c|c|c|c|c|c|}
\hline $\begin{array}{c}\mathrm{C} \\
(\%)\end{array}$ & $\begin{array}{c}\mathrm{Si} \\
(\%)\end{array}$ & $\begin{array}{c}\mathbf{M n} \\
(\%)\end{array}$ & $\begin{array}{c}\mathbf{P} \\
(\%)\end{array}$ & $\begin{array}{c}\mathrm{S} \\
(\%)\end{array}$ & $\begin{array}{c}\mathbf{C r} \\
(\%)\end{array}$ & $\begin{array}{c}\mathbf{M o} \\
(\%)\end{array}$ \\
\hline 0.163 & 0.134 & 0.224 & 0.018 & 0.015 & 0.106 & 0.027 \\
\hline $\mathbf{N i}$ & $\mathbf{A l}$ & $\mathbf{C u}$ & $\begin{array}{c}\mathbf{N b} \\
(\%)\end{array}$ & $\begin{array}{c}\mathbf{T i} \\
(\%)\end{array}$ & $\begin{array}{c}\mathbf{V} \\
(\%)\end{array}$ & $\begin{array}{c}\mathbf{F e} \\
(\%)\end{array}$ \\
\hline 0.095 & $<0.001^{* *}$ & 0.094 & $<0.002 * *$ & 0.007 & 0.012 & bal. \\
\hline
\end{tabular}

\subsection{Hasil Uji Kekerasan}


Tingkat kekerasan pada suatu material dapat ditunjukan dengan nilai yang dihasilkan pada pengujian yang digunakan, baik pengujian fisis maupun mekanis. Salah satu untuk mengetahui nilai kekerasan suatu material yaitu menggunakan uji kekerasan dengan metode Vickers, dimana piramida intan sebagai media identornya, kemudian menghasilkan gambar belah ketupat meliputi diagonal 1 dan diagonal 2 .

Pada tabel dan grafik dibawah menunjukan tingkat nilai kekerasan 4 spesimen pada permukaan material baja karbon rendah setelah dilakukan beberapa variasi melalui elektroda yang dilapisi oleh Nikel (Ni) dan penambahan Karbon (C) sebesar 4\%. Dari variasi modifikasi yang digunakan akan terlihat perbedaan nilai kekerasan yang terjadi.

Perbedaan tingkat kekerasan pada permukaan baja karbon rendah setelah dilakukan pengelasan dengan variasi modifikasi elektroda dapat dilihat pada tabel dan grafik di bawah ini.

Tabel 5. Nilai Kekerasan Vickers Spesimen Non Treatment

\begin{tabular}{|c|c|c|c|c|c|c|}
\hline No & Spesimen & Penusukan & $\mathrm{d} 1 / \mu \mathrm{m}$ & $\mathrm{d} 2 / \mu \mathrm{m}$ & $\begin{array}{c}\text { VHN } \\
(\mathrm{Kgf} / \mathrm{mm})\end{array}$ & $\begin{array}{c}\text { Rata Rata } \\
\text { VHN } \\
(\mathrm{Kgf} / \mathrm{mm})\end{array}$ \\
\hline \multirow{5}{*}{1} & \multirow{5}{*}{$\begin{array}{c}\text { Elektroda biasa } \\
\text { (E6013) }\end{array}$} & 1 & 297.6 & 258 & 120.1 & \multirow{5}{*}{132.28} \\
\hline & & 2 & 258 & 258 & 138.9 & \\
\hline & & 3 & 258.3 & 258.3 & 139.2 & \\
\hline & & 4 & 269.5 & 253.9 & 135.3 & \\
\hline & & 5 & 269.2 & 269.2 & 127.9 & \\
\hline \multirow{5}{*}{2} & \multirow{5}{*}{$\begin{array}{c}\text { Elektroda Nikel } \\
(\text { E6013+Ni) }\end{array}$} & 1 & 207.7 & 207.7 & 214.9 & \multirow{5}{*}{212.12} \\
\hline & & 2 & 205.4 & 220.8 & 204.1 & \\
\hline & & 3 & 212.5 & 212.4 & 205.4 & \\
\hline & & 4 & 211.7 & 205.9 & 212.6 & \\
\hline & & 5 & 203.6 & 203.6 & 223.6 & \\
\hline \multirow{5}{*}{3} & \multirow{5}{*}{$\begin{array}{l}\text { Elektroda } \\
\text { Carbon } \\
(\mathrm{E} 6013+\mathrm{C})\end{array}$} & 1 & 284.1 & 284.1 & 114.8 & \multirow{5}{*}{177.62} \\
\hline & & 2 & 214.4 & 216.5 & 199.7 & \\
\hline & & 3 & 217.4 & 217.4 & 196.1 & \\
\hline & & 4 & 219.8 & 219.8 & 184.6 & \\
\hline & & 5 & 244.2 & 194.7 & 192.9 & \\
\hline \multirow{5}{*}{4} & \multirow{5}{*}{$\begin{array}{c}\text { Elektroda } \\
\text { Karbon Nikel } \\
(\text { E6013+C+N) }\end{array}$} & 1 & 152.8 & 152.8 & 397.1 & \multirow{5}{*}{366.08} \\
\hline & & 2 & 160.8 & 160.8 & 358.5 & \\
\hline & & 3 & 160.8 & 152.9 & 376.8 & \\
\hline & & 4 & 178.7 & 149.4 & 344.5 & \\
\hline & & 5 & 163.3 & 160.6 & 353.5 & \\
\hline
\end{tabular}




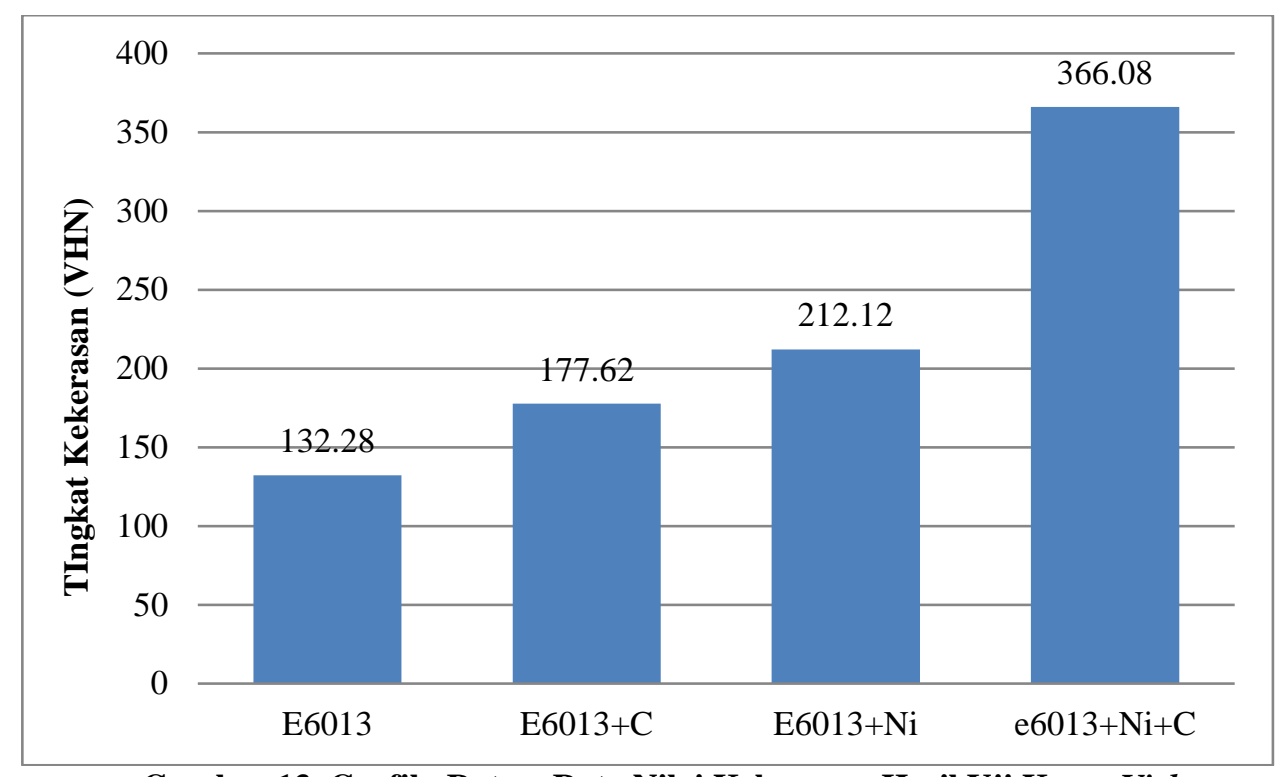

Gambar 13. Grafik Rata - Rata Nilai Kekerasan Hasil Uji Keras Vickers

Dari gambar 4.6 yaitu grafik yang menunjukan rata - rata nilai kekerasan, dapat dilihat bahwa nilai menunjukan tingkat kekerasan dari suatu material akan lebih tinggi setelah dilapisi nikel dan ditambah karbon.

Pada pengelasan permukaan baja karbon rendah menggunakan modifikasi elektroda yang dilapisi ini, nilai kekerasan yang tertinggi melalui uji kekerasan vickers adalah 366.08 VHN dengan Nikel (Ni) dan Karbon (C) sebagai bahan tambahnya, Kemudian tertinggi kedua yaitu plat yg dilas dengan elektroda E6013 yang dilapisi Nikel, dimana nilai yang dihasilkan adalah 212.12 VHN. Kemudian pada plat hasil las dengan elektroda E6013 yang ditambah Karbon mendapatkan nilai 177.62 VHN, Terakhir pada plat yang di las dengan elektroda E6013 tanpa adanya tambahan lain mendapatkan nilai 132.28 VHN.

\section{Kesimpulan \& Saran}

Dalam proses hardfacing dengan polaritas DC+ pada baja karbon rendah melalui proses pendinginan media air dan Non Treatment mendapatkan hasil sebagai berikut :

1. Tingkat kekerasan pada hasil las hardfacing dengan elektroda E6013 sebesar 132.28 VHN

2. Tingkat kekerasan pada hasil las hardfacing dengan elektroda E6013 yang dilapisi nikel sebesar 212.12 VHN.

3. Tingkat Kekerasan pada hasil las Hardfacing dengan ditambahkan karbon sebesar 177.62 VHN.

4. Dengan menambahkan Nikel dan Karbon kekerasan pada permukaan baja didapatkan hasil sebesar 366.08 VHN.

\section{Daftar Pustaka}

1. Adiansyahrie. (2010). Melakukan Rutinitas Pengelasan dengan Las Busur Manual. In Kompetensi Keahlian Teknik Pengelasan SMK Negeri 53 Jakarta (p. 46). Jakarta

2. Abbaschian, R., Robert, E., (1994) Physical Metalurgy Principles, Universitas of Florida, USA : PWS Publishing Company, Third Edition.

3. B.H Amstead dkk, Teknologi Mekanik, (1997) Jakarta : Erlangga

4. Daryanto, (2013) Teknik Las Bandung:Alfabeta

5. Dumrudkarn, C., \& Muangjunburee, P. (2015). Wear Behavior of Hardfacing Deposits on Hadfield Steel. In Key Engineering Materials (Vol. 658, pp. 172-176). Trans Tech Publications.

6. Edih Supardi dkk, (1996) Pengujian Logam Bandung :Angkasa

7.

8. Kirono, S., Eri, D., \& Isgihardi, P. (2010). Analisa perubahan dimensi Baja AISI 1045 setelah proses perlakuan panas (heat treatment). Universitas Muhammadiyah Jakarta Vol 4 No 2 , 1-11.

9. Iskandar, M. A. (2013). Analisa Sifat Fisis dan Mekanis Tooth Bucket Excavator Sebelum dan Sesudah Proses Heat Treatment. Tugas Akhir Universitas Muhammadiyah Surakarta, 1. 
Koswara ,Engkos, Sudjana, Hardi (1999) Pengujian Logam Bandung: Humaniora Utama Press Marwanto,A. (2007). Materi Lifeskill Las SMAW. Yogyakarta: Universitas Negeri Yogyakarta Mustopo, Y. D. (2011). Pengaruh Waktu terhadap Ketebalan dan Adhesivitas Lapisan pada Proses Elektroplating Khrom Dekoratif Tanpa Lapisan Dasar, dengan Lapisan Dasar Tembaga dan TembagaNikel

Napitupulu, R. A. M. (2005). Pengaruh Temperatur dan Waktu Pelapisan Terhadap Laju Pelapisan Nikel Pada Baja Karbon Rendah. Pengaruh Temperatur Dan Waktu Pelapisan Terhadap Laju Pelapisan Nikel Pada Baja Karbon Rendah.

Prayitno, D., Hutagalung, H. D., \& Aji, D. P.(2013) Pengaruh Kuat Arus Listrik Pengelasan Terhadap Kekerasan Lapisan Lasan pada Baja ASTM A316. Jurnal Dinamika Vokasional Teknik Mesin,

Rusmardi, R., \& Feidihal, F. (2012). Analisa persentase kandungan karbon pada logam baja. Jurnal Teknik Mesin,

Saleh, A. A. (1995). Pelapisan Logam. Buku Pegangan Industry Elektroplating, Balai Besar Pengembangan Industri Logam dan Mesin, Bandung.

Sugiyarta, S., Bayuseno, A. P., \& Nugroho, S. (2012). Pengaruh konsentrasi larutan dan kuat arus terhadap ketebalan pada proses pelapisan nikel untuk baja karbon rendah. ROTASI 